\section{The American Association for Thoracic Surgery}

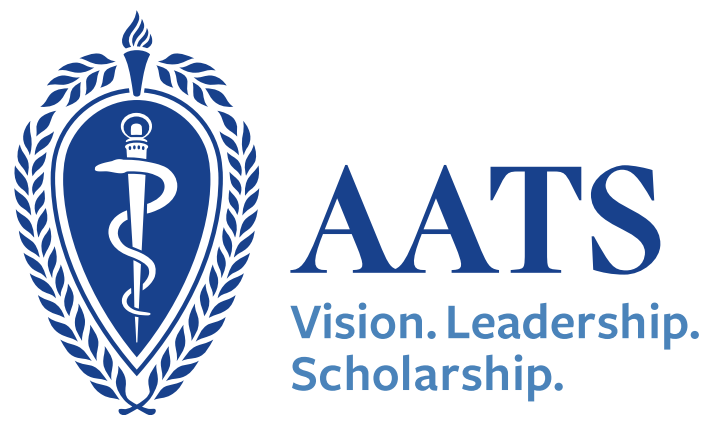

\section{AATS 100th Annual Meeting: A Virtual Learning Experience}

All presentations from the 100th Annual Meeting are now available on demand until September 23 on aats.org. Stay tuned for details on the 101st Annual Meeting and Aortic Symposium, taking place May 1-4, 2021, in Seattle, WA.

\section{View Updated Content on AATS Online}

You can now view presentations from the 2019 International Thoracic Surgical Oncology Summit and 2020 Mechanical Support for the Heart and Lung Symposium on AATS
Online. Access any of the presentations from the two-day meeting via the button below or go to AATS Online in the top navigation menu on the AATS Web site and select on Presentations from the drop-down menu. You will be prompted to $\log$ in and can use the available links if you do not know your user name and password.

To see the presentations from these or any other meeting, use the filter on the left side of the Presentation page to select the meeting from the drop-down menu and set the year. Refine your search further by using the search box to look for specific topics or presenters.

You can also search for other content on AATS Online including surgical videos, images, guidelines, and discussions with experts.

\section{Update Your AATS Profile}

Check that the information in your aats.org profile is current to ensure that you are receiving AATS information that is most important to you. By updating your contact information and sharing your areas of interest, you will be able to optimize your use of AATS Online and receive relevant AATS news. While you are in your profile, you can upload a recent photo, view your AATS activity, and more. To access your profile, log in using the "Sign In" or "My Account" link at the top of aats.org.

\section{The AATS Foundation}

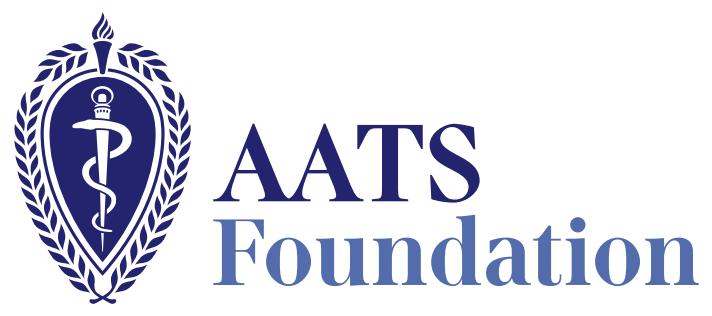

\section{Invest in the Future}

Thank you to those who have shown that you understand the importance of giving generously to support the next generation of cardiothoracic surgeons. As the end of the fiscal year quickly approaches, we challenge you to donate and underwrite the scholarship that advances the mission. There are a variety of options for donors who want to ensure the future of cardiothoracic surgery, including direct gifts, donated honoraria and stock, planned gifts, and tribute/memorial gifts. There are also opportunities to start a program in honor of a mentor or fund a named award that will support a surgical investigator.

The matching grant issued by the AATS remains active

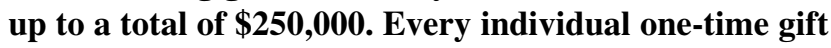

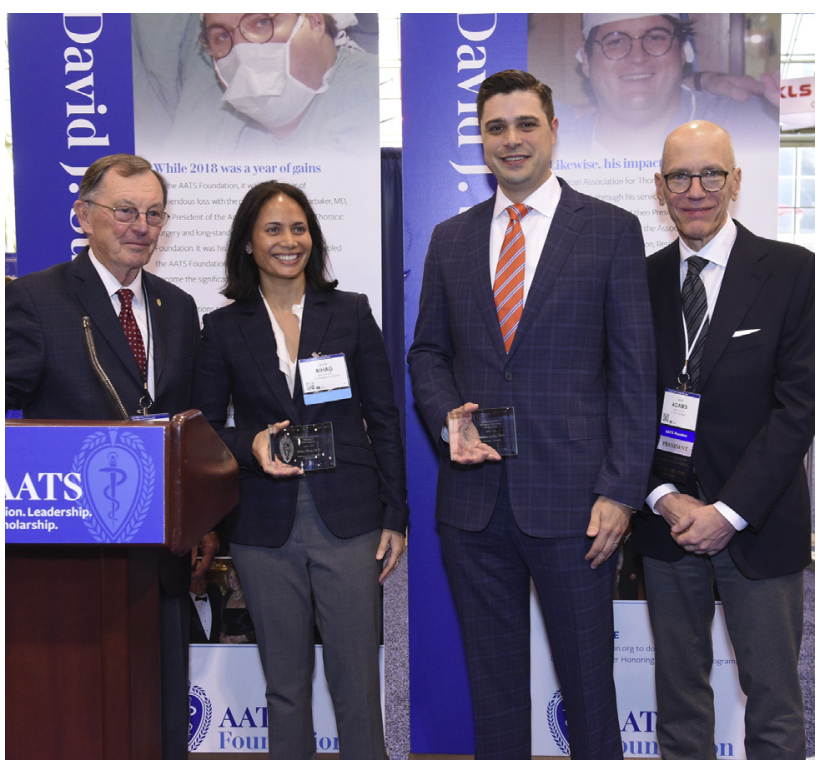

of $\$ 5,000$ or more will be doubled, making each dollar you contribute twice as valuable.

Learn more about the various ways to make a gift on aatsfoundation.org. 